\title{
Simulation of an abrupt change in Saharan vegetation in the mid-Holocene
}

\author{
Martin Claussen ${ }^{1}$, Claudia Kubatzki, Victor Brovkin, and Andrey Ganopolski \\ Potsdam-Institut für Klimafolgenforschung, Potsdam, Germany
}

Philipp Hoelzmann

Max-Planck-Insitut für Biogeochemie, Jena, Germany

\author{
Hans-Joachim Pachur \\ Institut für Geographie, Freie Universität Berlin, Germany
}

\begin{abstract}
Climate variability during the present interglacial, the Holocene, has been rather smooth in comparison with the last glacial. Nevertheless, there were some rather abrupt climate changes. One of these changes, the desertification of the Saharan and Arabian region some 4 6 thousand years ago, was presumably quite important for human society. It could have been the stimulus leading to the foundation of civilizations along the Nile, Euphrat and Tigris rivers. Here we argue that Saharan and Arabian desertification was triggered by subtle variations in the Earth's orbit which were strongly amplified by atmosphere- vegetation feedbacks in the subtropics. The timing of this transition, however, was mainly governed by a global interplay between atmosphere, ocean, sea ice, and vegetation.
\end{abstract}

\section{Introduction}

During the mid-Holocene some 9 - 6 thousand years ago (ka), the summer in many regions of the Northern Hemisphere was warmer than today. Palaeobotanic data indicate an expansion of boreal forests north of the modern treeline [Tarasov et al., 1998; Texier et al., 1997; Yu and Harrison, 1996]. In North Africa, data reveal a wetter climate [Hoelzmann et al., 1998]. Moreover, it has been found from fossil pollen [Jolly et al., 1998] that the Saharan desert was almost completely covered by annual grasses and low shrubs. The Sahel reached at least as far north as $23^{\circ} \mathrm{N}$. The wet phase ended around $4.5-4 \mathrm{ka}$ (uncalibrated ${ }^{14} \mathrm{C}$ data; approximately 5.0 - $4.5 \mathrm{ka}$ calibrated) in the high continental position of the East Sahara [Pachur and Altmann, 1997]. Estimates on the timing of the transition phase at the end of the mid-Holocene as well as its impacts on society vary. There are data which suggest that the transition to present-day's arid climate did not occur gradually, but in two steps with two arid episodes, at 6.7 to $5.5 \mathrm{ka}$ and at 4 to $3.6 \mathrm{ka}$ [Petit-Maire and Guo, 1996]. The latter was very severe, ruining ancient civilizations and socio-economic systems [Petit-Maire and Guo, 1996]. Other reconstructions [Malville et al., 1998] indicate an earlier exodus from the $\mathrm{Nu}-$

\footnotetext{
${ }^{1}$ Also at Institut für Meteorologie, Freie Universität Berlin, Germany.
}

Copyright 1999 by the American Geophysical Union.

Paper number 1999GL900494.

0094-8276/99/1999GL900494\$05.00 bian Desert around 4.8 ka but adaptation strategies of the Neolithic population by exploiting non-renewable groundwater resources seem to have extended settlement until $\mathbf{3 8 5 0}$ years ago. Freshwater lakes in the Eastern Sahara began to disappear from 5.7 until $4 \mathrm{ka}$, when recharge of aquifers ceased at the end of the wet phase. Reconstructions from continuous pollen sequences from Morocco [Cheddadi, 1998] indicate a strong increase in summer temperature and a strong decrease in precipitation around $6 \mathrm{ka}\left({ }^{14} \mathrm{C}\right.$ datum).

The transition from mid-Holocene to modern climate was triggered by changes in the Earth's orbit and the tilt of the Earth's axis [Street-Perrott et al., 1990; Kutzbach and Guetter, 1986]. Around $9 \mathrm{ka}$, the tilt of the Earth's axis was stronger than today and the time of perihelion was at the end of July [Berger, 1978]. This led to a stronger insolation of the Northern Hemisphere during summer which amplified the African and Indian summer monsoon. However, variations in orbital parameters through the Holocene are rather smooth, whereas changes in North African climate and vegetation were comparatively abrupt [see, e.g., Petit-Maire and Guo, 1996]. This suggests that there are feedbacks within the climate system which amplify and modify external forcing leading to marked climate variations. This hypothesis is based on earlier experiments using climate models which clearly reveal that positive feedbacks between climate and vegetation tend to amplify orbital forcing such that boreal climate becomes warmer (than without vegetationatmosphere feedback) [Foley et al., 1994; TEMPO Members, 1996; Texier et al., 1997] and North African climate becomes more humid during the mid-Holocene [Claussen and Gayler, 1997; Ganopolski et al., 1998a].

\section{Climate Simulations}

To analyze the feedbacks in the climate system operating during the last several thousand years we used a climate system model of intermediate complexity, CLIMBER2 (for CLIMate and BiosphERe, version 2) [Ganopolski et al., 1998a, b; Petoukhov et al., 1999]. We performed a set of consistent transient experiments with different model configurations, from an atmosphere-only version of the model to the fully coupled atmosphere-ocean-terrestrial vegetation model. CLIMBER-2 has a coarse resolution of 10 degrees in latitude and 51 degrees in longitude. The model encompasses a 2.5-dimensional dynamical-statistical atmosphere 

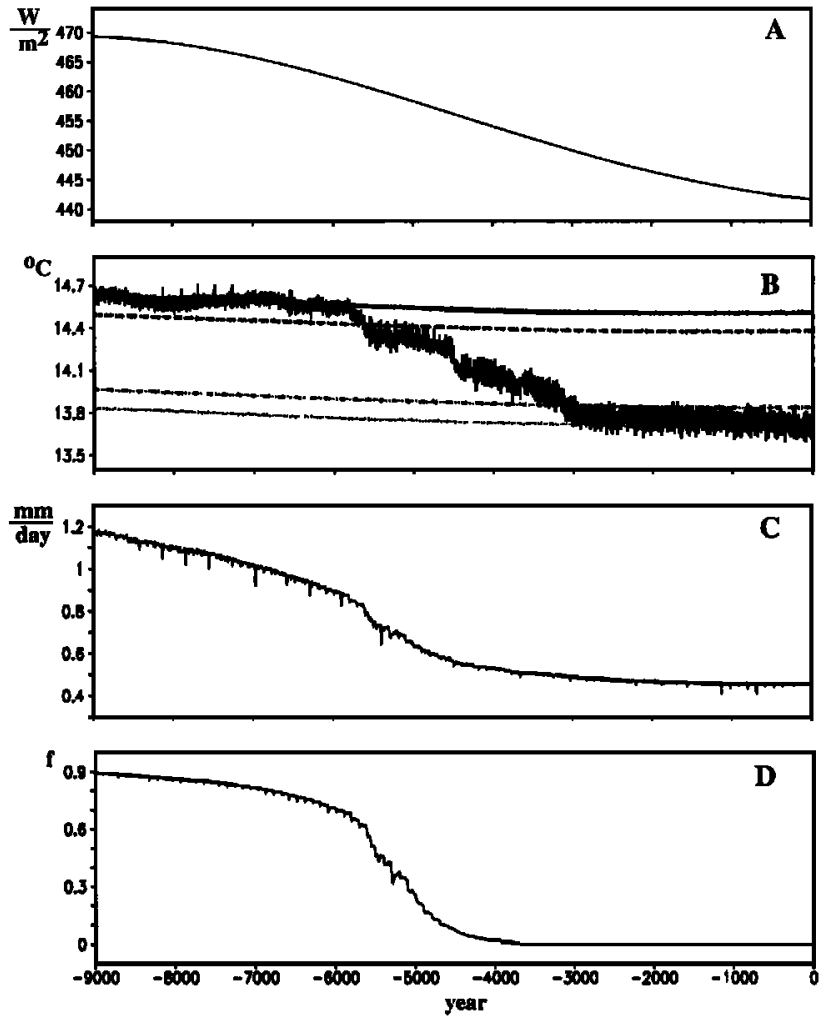

Figure 1. Summer (June, July, August) insolation (in $\mathrm{W} / \mathrm{m}^{2}$ ) on average over the Northern Hemisphere (A) and global near surface temperatures (in ${ }^{\circ} \mathrm{C}$ ) (B) simulated for the last 9000 years. For all simulations, areas of inland ice, aerosol concentration, and atmospheric $\mathrm{CO}_{2}$ are kept constant at preindustrial values. Only the solar insolation is varied according to changes in the Earth orbit. The smooth curves indicate results of the atmosphere-only model in which ocean surface and land surface are set to midHolocene values (thin full line) and to present-day values (dotted line). If ocean is at mid-Holocene and vegetation at present-day conditions, then global temperature follows the dashed line, in the reversed situation (ocean at presentday and vegetation at mid-Holocene), we obtain the dasheddotted line. In the fully coupled model, annual mean precipitation (in $\mathrm{mm} /$ day) (C) and fractional cover of vegetation (D) in the Sahara region (approximately $20^{\circ} \mathrm{N}-30^{\circ} \mathrm{N}$ and $15^{\circ} \mathrm{W}-50^{\circ} \mathrm{E}$ ) change much more abruptly than orbital forcing, due to internal feedbacks in the climate system

model, a multibasin, zonally averaged ocean model including sea ice, and, in contrast to [Ganopolski et al., 1998a], a dynamic model of terrestrial vegetation [Brovkin et al., $1997,1999]$. Vegetation cover is represented as a composition of trees, grass, and desert (bare soil).

CLIMBER-2 was started from an equilibrium with orbital forcing at $9 \mathrm{ka}$ and it was run in its fully coupled version for 9000 years until present day driven only by changes in orbital parameters [Berger, 1978]. While the latter determine the seasonal cycle of insolation (Fig.1, A), the other boundary conditions, distribution of inland ice and atmospheric $\mathrm{CO}_{2}$ concentration $(280 \mathrm{ppm})$, were kept constant at preindustrial values. Our model results indicate a slight decrease in global near surface temperatures of approximately
$0.1 \mathrm{~K}$ in 3000 years (Fig.1, B) until around $5.8 \mathrm{ka}$ when a stronger cooling (approximately $0.2 \mathrm{~K}$ in 300 years) appears, followed by a second event some 1000 years later. A similar trend and variations are seen in global precipitation. Obviously, these rather abrupt events are not correlated with the smooth changes in orbital forcing. Inspection of spatial patterns reveals that both cooling events occur mainly at high latitudes over the North Atlantic. The strongest reduction in precipitation over land, however, is seen in the region approximately $15^{\circ} \mathrm{W}-40^{\circ} \mathrm{E}$ and $20^{\circ} \mathrm{N}-30^{\circ} \mathrm{N}$, called the Sahara region in the following (Fig.1, C). Around $5.6 \mathrm{ka}$, when precipitation in this region decreases most strongly, a marked decrease in grassland appears (Fig.1, D). The fraction $f$ of vegetation cover in the Sahara becomes gradually smaller $(\Delta f \sim-0.25)$ for the first few thousand years of the simulation, then it decreases rather abruptly $(\Delta f \sim-0.3)$ within just 300 years starting at approximately $5.6 \mathrm{ka}$.

We repeated the transient simulation with different initial conditions. These were taken from different snapshots of the first run (at Dec 30th, $7999 \mathrm{ka}, 6999 \mathrm{ka}$, and so on). In each case, the orbital forcing and the simulation ran from $9 \mathrm{ka}$ to present. We find that the abrupt desertification is a robust event. In an ensemble of ten simulations, the abrupt desertification in North Africa begins at $5440 \pm 30$ years before present (Fig. 2).

\section{Sensitivity Experiments}

To analyze why desertification in North Africa is abrupt - in comparison with the rather smooth orbital forcing -, we performed a series of simulations exploring the dynamics of the atmosphere-only model (model A), the atmospherevegetation model $(\mathrm{AV})$ and the atmosphere- ocean model (AO), respectively. Firstly we have run the atmosphereonly model while keeping the ocean, i.e. the seasonal cycle of sea-surface temperatures (SST) and sea ice, as well as global vegetation pattern constant in time. In this case, the atmosphere follows orbital forcing rather smoothly (Fig.1, B). The same applies to global precipitation. Keeping sea-surface temperature, sea-ice, and vegetation at midHolocene values yields a generally warmer and wetter climate for the following reasons. Firstly, a warmer ocean surface directly warms the near-surface atmosphere. Secondly, a warmer ocean evaporates more water vapor which strengthens the greenhouse effect. Likewise, a more vegetated land surface appears to be darker than bare soil, which not only increases absorption of solar radiation but also evaporation and, finally, the greenhouse effect.

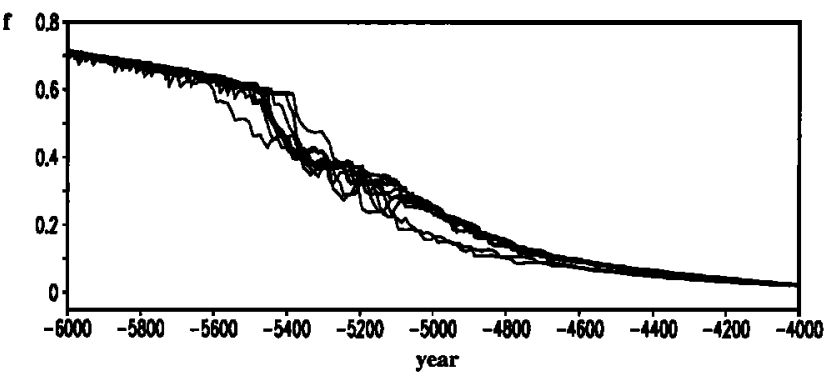

Figure 2. Fraction of vegetation cover in the Sahara as obtained from an ensemble of 10 simulations with the fully coupled model. Simulations differ only by their initial conditions, while orbital forcing remains the same 


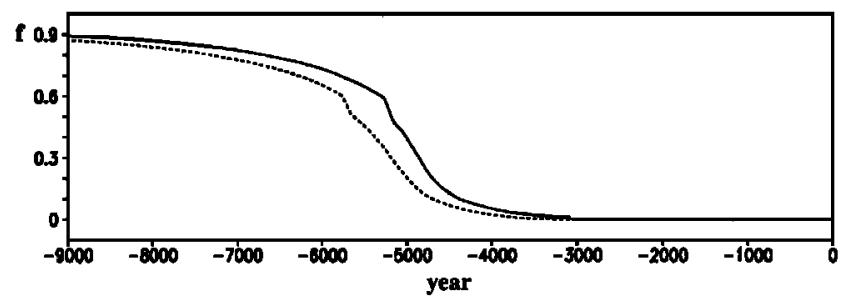

Figure 3. Fraction of vegetation cover in the Sahara region simulated by using the atmosphere-vegetation model. If the ocean surface, i.e. sea-surface temperatures and seaice coverage, is kept constant at mid-Holocene values (full line), then desertification starts a later than in the case of a present-day ocean surface (dashed line)

If we couple atmosphere and vegetation model (model AV), but keep the ocean surface characteristics as in model $A$, the annual global mean temperature and precipitation change more strongly than in model A, but still gradually. Only in the Sahara region we find an abrupt decrease in vegetation (Fig.3) from a green Sahara $(f>0.6)$ to a desert shrubland $(f<0.15)$ within a few hundred years. The abrupt regional change is caused by a feedback between subtropical vegetation and precipitation. This feedback emerges from an interaction between high albedo of $\mathrm{Sa}$ haran sand deserts and atmospheric circulation as hypothesized by Charney [1975] and from subsequent changes in the hydrological cycle [Claussen, 1997, 1998]. The biogeophysical feedback can work fast because of a quick - in comparison with deep ocean circulation - response time of vegetation in this region. In CLIMBER-2, the response time of the vegetation structure to climate changes is directly related to the turn-over time of biomass: semidesert vegetation has a biomass turnover of years to a decade (as compared to a century for boreal forests). However, the response time $\tau$ of vegetation is not the crucial factor determining Saharian desertification. The decrease of Saharan vegetation cover does not change substantially, if $\tau$ is increased to a value typical for boreal forests. Only if we intentionally increase the response time of semidesert vegetation to unrealistically large values, of several hundred years, then climate and vegetation in North Africa react more smoothly to orbital forcing. At northern high latitudes, boreal forests cease gradually during the Holocene, although the response time would allow for a faster change.

Numerical studies with a high-resolution, comprehensive atmosphere-vegetation model [Claussen, 1998] reveal that the biogeophysical feedback is strongest in the western part of the Sahara, leading to two stable solutions, a green solution and a desert solution, in present-day climate. For mid- Holocene conditions, only a green solution is possible [Claussen, 1997; Claussen et al, 1998]. When analyzing the stability of equilibrium solutions in North-West Africa, it was found [Brovkin et al., 1998] that two solutions appear already around $6 \mathrm{ka}$ which implies the possibility of jumplike transitions between the green and the desert state in the western Sahara at the end of the mid-Holocene. Because the horizontal resolution in CLIMBER-2 is too coarse to distinguish between western and eastern Sahara, we find only one, albeit quickly varying, solution at any time for the (entire) Sahara region.
The reasons for these abrupt vegetation changes are, by and large, the same in the $\mathrm{AV}$ and the AOV experiments. However in model AV, the timing of desertification depends on SST and sea-ice conditions. The Saharan desertification occurs earlier, around $5.8 \mathrm{ka}$, if SST and sea ice are kept at present-day values (run AV-S0k). If SST and sea ice are prescribed at mid-Holocene values, i.e. at 9ka (run AV$\mathrm{S} 9 \mathrm{k}$ ), the transition is found later, at around $5.3 \mathrm{ka}$ (Fig. 3). This result is independent of initial conditions. On annual and global average, we find a warmer and wetter climate in AV-S9k than in AV-S0k - for reasons similar to what was described in the atmosphere-only simulations. Moreover the large-scale meridional temperature gradients differ: the strongest temperature differences between AV-S9k and AV-SOk can be found at high northern latitudes (some $2.5^{\circ} \mathrm{C}$ on zonal average), while only small differences are seen in the tropics and subtropics (some $0.3^{\circ} \mathrm{C}$ on zonal average). Because the area of Arctic sea ice is smaller (by some $3 \cdot 10^{6}$ $\mathrm{km}^{2}$ ) in AV-S9k than in AV-SOk and the Arctic SSTs are higher, the climate at high northern latitudes is warmer. Subsequently, boreal tree cover is always larger in AV-S9k than in AV-SOk at the expense of tundra and bare soil. As the albedo of snow-covered trees is much lower than that of snow-covered tundra or bare soil, summer warming over northern Eurasia is amplified - as already found in earlier studies [TEMPO Members, 1996; Ganopolski et al., 1998a; deNoblet et al., 1996]. Hence owing to the vegetation-snowalbedo feedback, the seasonal large-scale meridional temperature pattern and the African and Asian summer monsoon, stay closer - and longer - to mid-Holocene conditions in AVS9k than in AV-S0k. Thus we conclude that conditions at high northern latitudes contribute to the timing of Saharan desertification in model AV.

In the fully coupled model (model AOV), the timing depends on a global interplay between atmosphere, ocean and vegetation. Starting from mid-Holocene conditions, the summer cooling at high northern latitudes due to orbital forcing is amplified by a southward migration of boreal forests. In contrast to simulation AV-S9k, the Arctic sea ice responds to this trend. The sea-ice area expands, thereby further amplifying the initial cooling. This synergism between vegetation-snow- albedo feedback and sea-ice-albedo feedback finally, by changing large-scale temperature distributions, leads to an earlier transition in Saharan vegetation than observed in AV-S9k. The same reasoning, but with opposite sign, can explain differences in timing between model $\mathrm{AOV}$ and AV-SOk.

If we couple atmosphere and ocean model (model AO), but keep the global vegetation pattern constant in time, then we do not find any abrupt change in the subtropics. Hence we can safely state that the abrupt transition in Saharan climate at the end of the mid-Holocene can be traced back to the time evolution of an atmosphere-vegetation feedback in which the ocean plays only a minor role.

\section{Conclusions}

In conclusion, our results indicate that the long-term cooling and drying from mid-Holocene to present-day is triggered by subtle changes in the Earth's orbit. However, the abrupt desertification in North Africa during the mid-Holocene can be explained only in terms of internal, mainly regional, vegetation-atmosphere feedbacks in the cli- 
mate system whereas the timing of this event depends on the state of the global climate system. Further experiments are necessary to more precisely quantify the contribution of low latitudes versus high northern latitudes, oceanic feedbacks versus biospheric feedbacks, to the timing.

Our simulations suggest that Saharan desertification, the largest change in land cover during the last 6000 years, was a natural phenomenon as it can be described in terms of climate-system dynamics only. Although humans lived in the Sahara and used the land to some extent, we hypothesize that ancient land use played only a negligibly small role in mid-Holocene Saharan desertification.

Acknowledgments. We thank S. Rahmstorf, PotsdamInstitut für Klimafolgenforschung, and A. Berger, Université Catholique, Louvain-la-Neuve, for constructive comments.

\section{References}

Berger, A., Long-term variations of daily insolation and quaternary climatic changes, J. Atmos. Sci., 35, 2362-2367, 1978.

Brovkin, V., Ganopolski, A., Svirezhev, Yu., A continuous climate- vegetation classification for use in climate-biosphere studies. Ecol. Modell., 101, 251-261, 1997.

Brovkin V., M. Claussen, V. Petoukhov, A. Ganopolski, On the stability of the atmosphere - vegetation system in the Sahara/Sahel region, J. Geophys. Res., D24, 31613-31624, 1998.

Brovkin, V., A. Ganopolski, W. von Bloh, A. Bondeau, M. Claussen, W. Cramer, V. Petoukhov, S. Rahmstorf, and Yu. Svirezhev, VEgetation COntinuous DEscription Model (VECODE): Technical Report, PIK Report, Potsdam-Institut für Klimafolgenforschung, Germany, in preparation.

Charney, J.G., Dynamics of deserts and drought in the Sahel, Quart. J. R. Met. Soc., 101, 193-202, 1975.

Cheddadi, R., Lamb, H.F., Guiot, J., van der Kaars, S., Holocene climatic change in Marocco: a quantitative reconstruction from pollen data. Clim. Dyn., 14, 883-890, 1998.

Claussen, M., Modeling biogeophysical feedback in the African and Indian Monsoon region, Clim. Dyn., 13, 247-257, 1997.

Claussen, M. and Gayler, V., The greening of Sahara during the mid-Holocene: results of an interactive atmosphere - biome model, Global Ecol. and Biogeography Lett., 6, 369-377, 1997.

Claussen, M., On multiple solutions of the atmosphere-vegetation system in present-day climate, Global Change Biol., 4, 549 $-559,1998$.

Claussen, M., V. Brovkin, A. Ganopolski, C. Kubatzki, and V. Petoukhov, Modeling global terrestrial vegetation-climate interaction, Philos. Trans. R. Soc. London, Ser. B, 353, 53-63, 1998.

Foley, J., J.E. Kutzbach, M.T. Coe, and S. Levis, Feedbacks between climate and boreal forests during the Holocene epoch, Nature, 371, 52-54, 1994.

Ganopolski, A., Kubatzki, C., Claussen, M., Brovkin, V., and Petoukhov, V., The influence of vegetation-atmosphere-ocean interaction on climate during the mid-Holocene, Science, 280 , 1916-1919, 1998a.

Ganopolski, A., Rahmstorf, S., Petoukhov, V., and Claussen, M., Simulation of modern and glacial climates with a coupled global model of intermediate complexity, Nature, 391, 351-356, 1998b.

Hoelzmann, P., D. Jolly, S.P. Harrison, F. Laarif, R. Bonnefille, and H.-J. Pachur, Mid-Holocene land-surface conditions in northern Africa and the Arabian Peninsula: A data set for the analysis of biogeophysical feedbacks in the climate system, Global Biogeochem. Cycles, 12, 35-52, 1998.
Jolly, D. et al., Biome reconstruction from pollen and plant macrofossil data for Africa and the Arabian peninsula at 0 and $6 \mathrm{ka}, J$. of Biogeography, 25, 1007-1027, 1998.

Kutzbach J.E., and Guetter P.J., The influence of changing orbital parameters and surface boundary conditions on climate simulations for the past 18,000 years, J. Atmos. Sci.,43, 1726$1759,1986$.

Malville, J.M., Wendorf, F., Mazar, A.A., and Schild, R., Megaliths and Neolithic astronomy in southern Egypt Nature, 392, 488-491, 1998.

deNoblet, N., I.C. Prentice, S. Jousaume, D. Texier, A. Botta, and $A$. Haxeltine, Possible role of atmosphere-biosphere interactions in triggering the last glaciation, Geophys. Res. Lett., 23, 3191-3194, 1996.

Pachur, H.-J., and N. Altmann, The Quaternary (Holocene, ca. 8000 a BP) in Palaeogeographic-Palaeotectonic atlas of NorthEastern Africa, Arabia, and Adjacent Areas Late Neoproterozoic to Holocene, edited by H. Schandelmeier and P.-O. Reynolds, pp. 111-125, A.A.Balkema, Rotterdam/Brookfield, 1997.

Petit-Maire, N., and Z. Guo, Mise en evidence de variations climatiques holocenes rapides, en phase dans les deserts actuels de Chine et du Nord de lAfrique, Sciences de la Terre et des Planetes, 322, 847-851, 1996.

Petoukhov, V., A. Ganopolski, V. Brovkin, M. Claussen, A. Eliseev, C. Kubatzki, S. Rahmstorf, CLIMBER-2: a climate system model of intermediate complexity. Clim. Dyn.,1999 (accepted).

Street-Perrott, F.A., J. F. B. Mitchell, D. S. Marchand, and J. S. Brunner, Milankovitch and albedo forcing of the tropical monsoon: a comparison of geological evidence and numerical simulations for $9000 \mathrm{yr}$ BP. Trans. of the Royal Soc. of Edinburgh (Earth Sciences), 81, 407 - 427, 1990.

Tarasov P.E., et al., Present day and mid-Holocene biomes reconstructed from pollen and plant macrofossil data from the former Soviet Union and Mongolia, J. of Biogeography, 25, 1029-1053, 1998.

TEMPO, 1996, Potential role of vegetation feedback in the climate sensitivity of high-latitude regions: A case study at 6000 years B.P., Global Biogeochem. Cycles, 10, 727-736.

Texier, D., N. deNoble, S.P. Harrison, A. Haxeltine, D. Jolly, S. Joussaume, F. Laarif, I.C. Prentice, and P. Tarasov, Quantifying the role of biosphere-atmosphere feedbacks in climate change: Coupled model simulations for 6000 years BP and comparison with palaeodata for northern Eurasia and Africa, Clim. Dym., 13, 865-882, 1997.

Yu, G. and S. P. Harrison, An evaluation of the simulated water balance of Eurasia and northern Africa at 6000 y BP using lake status data, Clim. Dyn., 12, 723-735, 1996.

M. Claussen, C. Kubatzki, V. Brovkin, and A. Ganopolski, Potsdam-Institut für Klimafolgenforschung, Postfach 601203, D-14412 Potsdam, Germany, (e-mail: claussen@pik-potsdam.de; kubi@pik-potsdam.de; victor@pik-potsdam.de; andrey@ pik-potsdam.de)

P. Hoelzmann, Max-Planck-Institut für Biogeochemie, Tatzendpromenade 1a, D-07745 Jena, Germany, (e-mail: hoelzmann@bgc-jena.mpg.de)

H.-J. Pachur, Institut für Geographie, FU Berlin, Altenstein Str. 19, D-14195 Berlin, Germany

(Received May 19, 1999; accepted May 25, 1999.) 